\section{BACTERIÓFAGOS Y ENDOLISINAS EN LA INDUSTRIA ALIMENTARIA}

Diana Gutiérrez Fernández

Instituto de Productos Lácteos de Asturias

Consejo Superior de Investigaciones Científicas ORCID iD: https://orcid.org/0000-0002-0473-1447

dianagufer@ipla.csic.es

Lucía Fernández Llamas

Instituto de Productos Lácteos de Asturias Consejo Superior de Investigaciones Científicas ORCID iD: https://orcid.org/0000-0002-7383-7595

lucia.fernandez@ipla.csic.es

Ana Rodríguez González

Instituto de Productos Lácteos de Asturias Consejo Superior de Investigaciones Científicas ORCID iD: https://orcid.org/0000-0002-1577-9905 anarguez@ipla.csic.es

Pilar García Suárez

Instituto de Productos Lácteos de Asturias Consejo Superior de Investigaciones Científicas ORCID iD: https://orcid.org/0000-0003-1213-8165

pgarcía@ipla.csic.es

Cómo citar este artículo/Citation: Gutiérrez Fernández, D., Fernández Llamas, L., Rodríguez González, A., y García Suárez, P. (2020). Bacteriófagos y endolisinas en la industria alimentaria. Arbor, 196 (795): a544. https://doi.org/10.3989/ arbor.2020.795n1008

Recibido: 26 febrero 2019. Aceptado: 29 octubre 2019.

RESUMEN: La obtención de alimentos sanos y seguros requiere de técnicas de conservación inocuas para el consumidor y para el medio ambiente, entre las que se destaca la bioconservación. A su catálogo de compuestos naturales o microorganismos, utilizados de forma habitual, la bioconservación ha incorporado recientemente los bacteriófagos (fagos) y las proteínas fágicas con actividad lítica (endolisinas). La utilización de fagos y endolisinas en el biocontrol ofrece importantes ventajas frente a otros sistemas de conservación tradicionales. Entre dichas ventajas destacan su inocuidad, especificidad y versatilidad. Por otra parte, la acuciante necesidad de reducir el uso de antibióticos en la cadena alimentaria ha impulsado la investigación basada en estos antimicrobianos con el fin de aplicarlos en producción primaria (terapia fágica). Sin embargo, y a pesar de la gran eficacia ya demostrada en múltiples sectores, la falta de legislación de la Unión Europea sobre el uso de bacteriófagos junto con la necesidad de ser aceptados por los consumidores, son factores que están afectando negativamente a su implantación como bioconservantes. En este contexto, este artículo recoge los últimos resultados relacionados con este tipo de antimicrobianos en la industria agro-alimentaria, y resume los puntos clave para entender las posibilidades reales de su aplicación ante los nuevos requisitos asociados con una producción sostenible tanto desde una perspectiva económica como ambiental.

PALABRAS CLAVE: bacteriófago; endolisina; antimicrobiano; resistencia antimicrobiana; bacteria patógena; sostenibilidad.

\section{BACTERIOPHAGES AND ENDOLYSINS IN THE FOOD INDUSTRY}

Copyright: () 2020 CSIC. Este es un artículo de acceso abierto distribuido bajo los términos de la licencia de uso y distribución Creative Commons Reconocimiento 4.0 Internacional (CC BY 4.0).

ABSTRACT: The production of healthy and safe food requires using preservation techniques that are harmless to consumers and the environment, with biopreservation as a perfect example. In addition to a long list of natural compounds and microorganisms, bacteriophages (phages) and phage-lytic proteins (endolysins) have recently been incorporated into the biopreservation arsenal. The use of phages and endolysins in biocontrol offers important advantages over other traditional preservation techniques. For example, these antimicrobials are harmless, target-specific and versatile. On the other hand, the need to curtail antibiotic use along the food production chain has promoted research initiatives with the ultimate aim of applying these antimicrobials in primary production (phage therapy). However, despite their demonstrated efficacy in different sectors, the current legal vacuum in the EU and the lack of information given to consumers are negatively affecting their implementation as biopreservatives. In this context, this chapter includes the latest results related to the use of these antimicrobials in the agro-food sector and summarises key points that will help to understand the real prospects for their application, considering new requirements to move towards sustainable production from both an economic and an environmental perspective.

KEYWORDS: bacteriophage; endolysin; antimicrobial; antimicrobial resistance; pathogenic resistance; sustainability. 


\section{INTRODUCCIÓN}

La sociedad actual se enfrenta a uno de los retos más importantes de su historia, el cual es proporcionar alimentos a una población que se prevé que alcance los 9.700 millones de personas en 2050. La disponibilidad de una gran cantidad de alimentos que satisfaga esta gran demanda se ve amenazada, entre otros factores, por el impacto que su producción puede tener en el suelo, en el suministro de agua y en la emisión de gases que, sin duda, acelerarían el cambio climático. Estas circunstancias han contribuido enormemente a que la economía circular y sostenible se encuentre actualmente entre los principales temas de trabajo en la agenda de la Comisión Europea (Food 2030, http://ec.europa.eu/research/bioeconomy/index.cfm?pg=policy\&lib=food2030). En este contexto, la optimización de recursos es esencial, así como la reducción del impacto medioambiental que supone la obtención y el procesamiento de los alimentos.

A la propia dificultad de conseguir una producción de alimentos sostenible, se suman los efectos negativos que la producción intensiva de algunos productos está teniendo en el ambiente y en la salud humana. Así, por ejemplo, el uso indiscriminado de antibióticos como promotores del crecimiento en animales de granja ha desencadenado un incremento alarmante de bacterias patógenas resistentes a antibióticos, las cuales representan un alto riesgo para la salud humana por lo que tienen una gran importancia clínica. Consecuentemente, en el futuro próximo es imprescindible reemplazar el uso de antibióticos en ganadería por otro tipo de antimicrobianos que eviten el incremento de bacterias resistentes, siendo este uno de los principales objetivos del Plan de Acción Global de Resistencia a Antibióticos impulsado por la Organización Mundial de la Salud (OMS) (https://www.who.int/antimicrobial-resistance/ global-action-plan/en/). De modo similar, es probable que los desinfectantes utilizados por la industria alimentaria que son vertidos al medioambiente hayan contribuido también a la selección de bacterias resistentes a los antibióticos (Bore et al., 2007).

Este cambio progresivo en las políticas de control de patógenos que, a priori, conlleva una serie de ventajas, debe garantizar también la calidad higiénicosanitaria de los alimentos de una manera igual de estricta. A pesar de estos cambios, las enfermedades transmitidas por los alimentos siguen siendo un grave problema a nivel mundial, con altas tasas de morbilidad y mortalidad, y con un notable impacto en el desarrollo socioeconómico de muchos países. La OMS estimó que en el año 2010 se produjeron 600 millones de casos de enfermedades de transmisión alimentaria y 420.000 muertes. Las causas más frecuentes fueron norovirus y Campylobacter spp., seguidas por Salmonella enterica no tifoidea, Salmonella Typhi, Taenia solium, el virus de la hepatitis A y las aflatoxinas (http:// www.who.int/foodsafety/areas_work/foodbornediseases/ferg/en/). En lo que respecta a Europa, en el año 2016 el último informe de la EFSA recoge 4.786 brotes de intoxicaciones alimentarias, siendo los agentes causantes más frecuentes Campylobacter spp. y Salmonella (EFSA and ECDC, 2017). En países no comunitarios la situación es semejante, detectándose solo en Estados Unidos 20.098 casos confirmados, con 4.598 hospitalizaciones y 77 fallecidos en 2015 (véase Foodborne Diseases Active Surveillance Network).

Por otra parte, las demandas de los consumidores en los países desarrollados han cambiado radicalmente en los últimos años. La tendencia hacia una alimentación más sana va acompañada de una preferencia por productos que contengan cada vez menos conservantes de síntesis química. Los nuevos modelos de sociedad demandan, cada vez más, productos recién cosechados y listos para el consumo. Finalmente, la globalización de los mercados permite a los consumidores obtener una mayor variedad de productos, que son exportados desde grandes distancias, lo que necesariamente implica un nuevo enfoque en el procesado y conservación de los alimentos.

Como contrapartida a los desafíos que supone mantener y mejorar la seguridad alimentaria, se ha realizado un gran esfuerzo durante los últimos años consistente en la introducción de nuevas medidas de control de los alimentos, pero también en un mejor conocimiento de la microbiología de los microorganismos presentes en los mismos, y en el desarrollo de técnicas cada vez más sofisticadas de identificación de patógenos. Por todo ello, las tecnologías tradicionales de conservación de alimentos están evolucionando hacia otras nuevas que complementen a las actuales, sobre todo en aquellos aspectos que las tecnologías clásicas no pueden abordar, y ofreciendo al consumidor un producto acorde a su demanda.

En este artículo presentamos el uso de productos fágicos como una alternativa de conservación factible y complementaria a los sistemas actuales, que aprovecha las propiedades antimicrobianas que presentan los bacteriófagos y las endolisinas, para aplicarlas en alimentos y extender su vida útil, y que tiene en cuenta también su versatilidad para reducir la llegada de bacterias patógenas a los mismos desde otros puntos de la cadena alimentaria. 


\section{LOS BACTERIÓFAGOS}

Los bacteriófagos son virus que infectan específicamente a bacterias. Se trata de los microorganismos más abundantes del planeta (Brüssow y Kutter, 2005), por lo que se encuentran ampliamente distribuidos en todos los ambientes, incluidos los alimentos. Forman parte de todos los ecosistemas naturales, donde ejercen un papel modulador de las poblaciones bacterianas, y también se encuentran presentes como parte de nuestra microbiota (Manrique, Dills y Young, 2017). Por lo tanto, los bacteriófagos son inocuos para los humanos, los animales y las plantas.

Existe una gran diversidad de fagos que ya han sido identificados hasta el momento y que se han clasificado en trece familias en función de la morfología de la partícula viral y de la composición de su material genético. La mayoría de los fagos pertenecen al orden Caudovirales, y constan de cabeza icosaédrica y cola, ambas formadas por proteínas. Su material genético es una molécula de ADN de cadena doble. Dentro de este orden se distinguen tres familias en función de la morfología de la cola: Myoviridae, con cola contráctil,
Siphoviridae, con cola larga no contráctil y Podoviridae, con cola corta. Otros fagos presentan morfología cúbica, filamentosa o pleomórfica y su material genético puede ser ADN o ARN de cadena sencilla o doble (Ackermann, 2007).

La capacidad lítica de los bacteriófagos está ligada a la naturaleza de su ciclo de vida. En términos generales, los bacteriófagos pueden clasificarse en función de su ciclo de vida en fagos virulentos y atemperados. Los primeros pueden realizar únicamente un ciclo de vida lítico (véase figura 1), es decir, una vez que infectan a la bacteria huésped, se multiplican dentro de ella para dar lugar a una progenie viral que será liberada al exterior de la bacteria, en la mayoría de los casos, tras la lisis de la misma. Los principales estadios dentro del ciclo lítico de un fago son: a) adsorción del fago a la superficie de la bacteria mediante el reconocimiento de receptores específicos; b) inyección del material genético al interior del citoplasma de la bacteria; c) replicación del genoma fágico dando lugar a múltiples copias; d) síntesis de las proteínas estructurales y ensamblaje de las partículas virales; f) liberación de la progenie viral tras la lisis de la bacteria.

Figura 1. Representación gráfica de los ciclos de vida de un bacteriófago de la familia Myoviridae en una bacteria Gram positiva

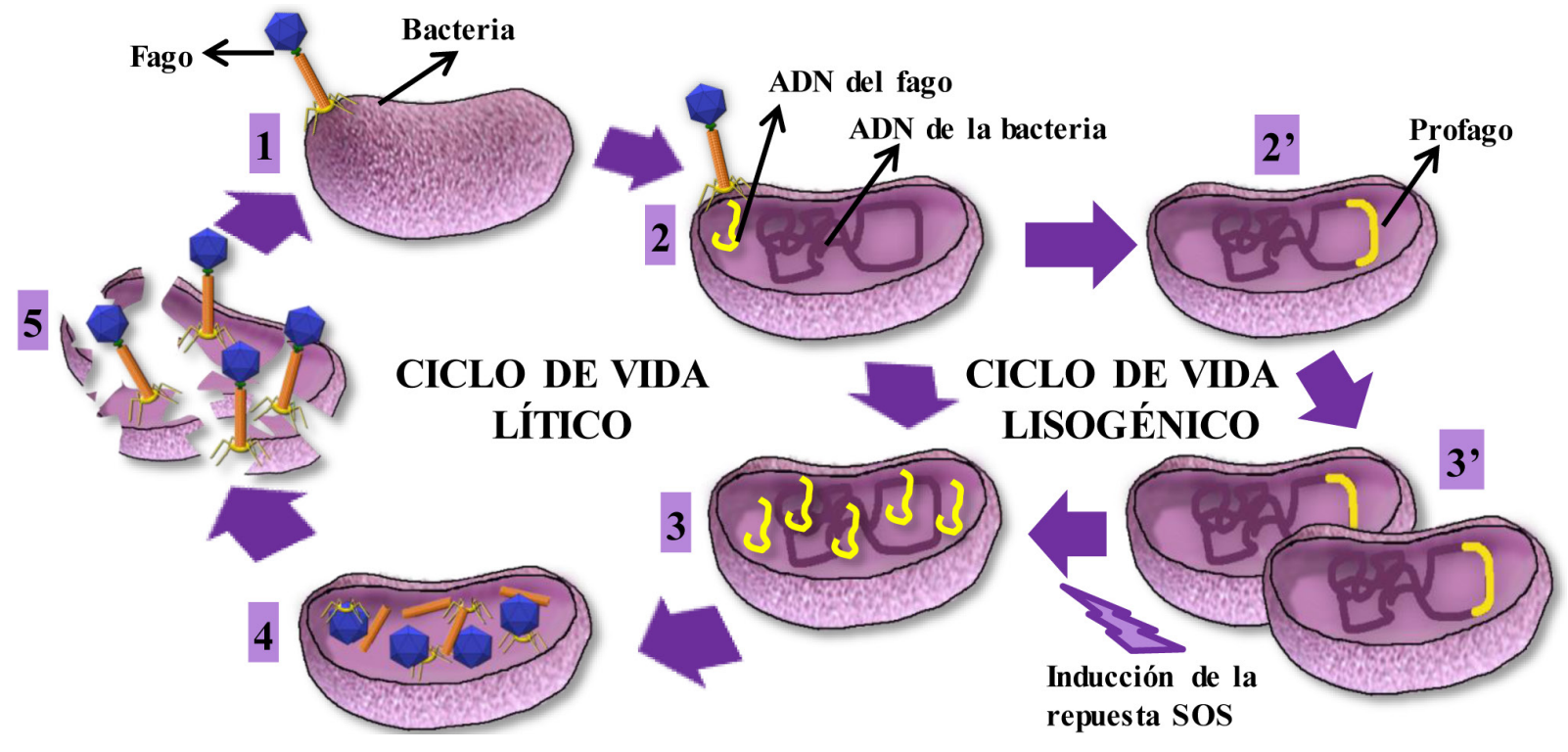

El ciclo de vida lítico llevado a cabo por los fagos virulentos tiene cinco etapas: 1) Adsorción del fago a la bacteria. 2) Inyección del material genético del fago en la bacteria. 3) Replicación del material genético del fago en el interior de la bacteria. 4) Síntesis y ensamblaje de las nuevas partículas fágicas. 5) Lisis bacteriana y liberación de la progenie viral. Por otro lado, el ciclo de vida lisogénico llevado a cabo por los fagos atemperados tiene dos pasos extra: 2') tras la inyección del material genético del fago en el interior de la bacteria, este se integra en el cromosoma bacteriano en forma de profago. $3^{\prime}$ ) La bacteria se divide dando lugar a dos bacterias con el profago insertado en su genoma. Un estrés ambiental puede inducir la respuesta SOS activando la liberación del profago y desencadenando el ciclo lítico.

Fuente: elaboración propia. 
Los fagos atemperados, por otro lado, tras infectar a la bacteria huésped tienen la capacidad de realizar o bien el ciclo de vida lítico o el lisogénico (véase figura 1). En este último, el ADN del fago, una vez en el interior de la bacteria, se integra en el genoma bacteriano mediante una recombinación sitio-específica. Este estado de latencia se conoce como lisogenia y el fago en este estado se denomina profago, pudiendo de este modo replicarse al mismo tiempo que el genoma de la bacteria y permanecer latente durante un tiempo indeterminado. Además, las bacterias en estado lisogénico (lisógenos) son inmunes a la infección por fagos de la misma familia. Esto significa que una parte de la población bacteriana no solamente no muere por la acción de estos fagos, sino que se hace resistente a ellos. No obstante, este estado de lisogenia puede revertir ante ciertas señales externas, como por ejemplo aquellas que inducen la respuesta SOS. En ese momento, el fago puede iniciar un ciclo de vida lítico, para lo cual escindirá su genoma del de la bacteria e iniciará la replicación del mismo, continuando con el resto de fases del ciclo lítico anteriormente descrito. Dado que estos fagos pueden o no lisar a la bacteria cuando la infectan, no son la mejor elección cuando se quieren aplicar como antimicrobianos.

\section{LAS ENDOLISINAS}

Son las proteínas fágicas encargadas de llevar a cabo el último paso del ciclo lítico de los fagos no filamentosos, en el que tiene lugar la liberación de la progenie viral. En fagos con ADN de doble cadena se sintetizan dos proteínas: holina y endolisina. La primera tiene afinidad por la membrana bacteriana, en la que se inserta haciendo poros, a través de los cuales pasará la endolisina al espacio periplásmico, desde donde degrada el peptidoglicano de la pared celular. Esto ocasiona que aumente la presión osmótica en el interior de la bacteria, lo que finalmente provoca la lisis de la misma (véase figura 2). En algunos fagos las holinas forman poros de pequeño tamaño que no permiten el paso de las endolisinas, pero sí de iones que cambian el potencial de membrana y activan de este modo la acción de las mismas. En este caso, las endolisinas contienen un péptido señal que les permite salir al exterior de la bacteria mediante los sistemas generales de secreción (Catalao, Gil, Moniz-Pereira, Sao-Jose y Pimentel, 2013; Sao-Jose, Parreira, Vieira y Santos, 2000).

La actividad enzimática de las endolisinas consiste en la hidrólisis del peptidoglicano que rodea a las

Figura 2. Representación esquemática del sistema holina/endolisina encargado de la lisis desde dentro de una bacteria Gram positiva

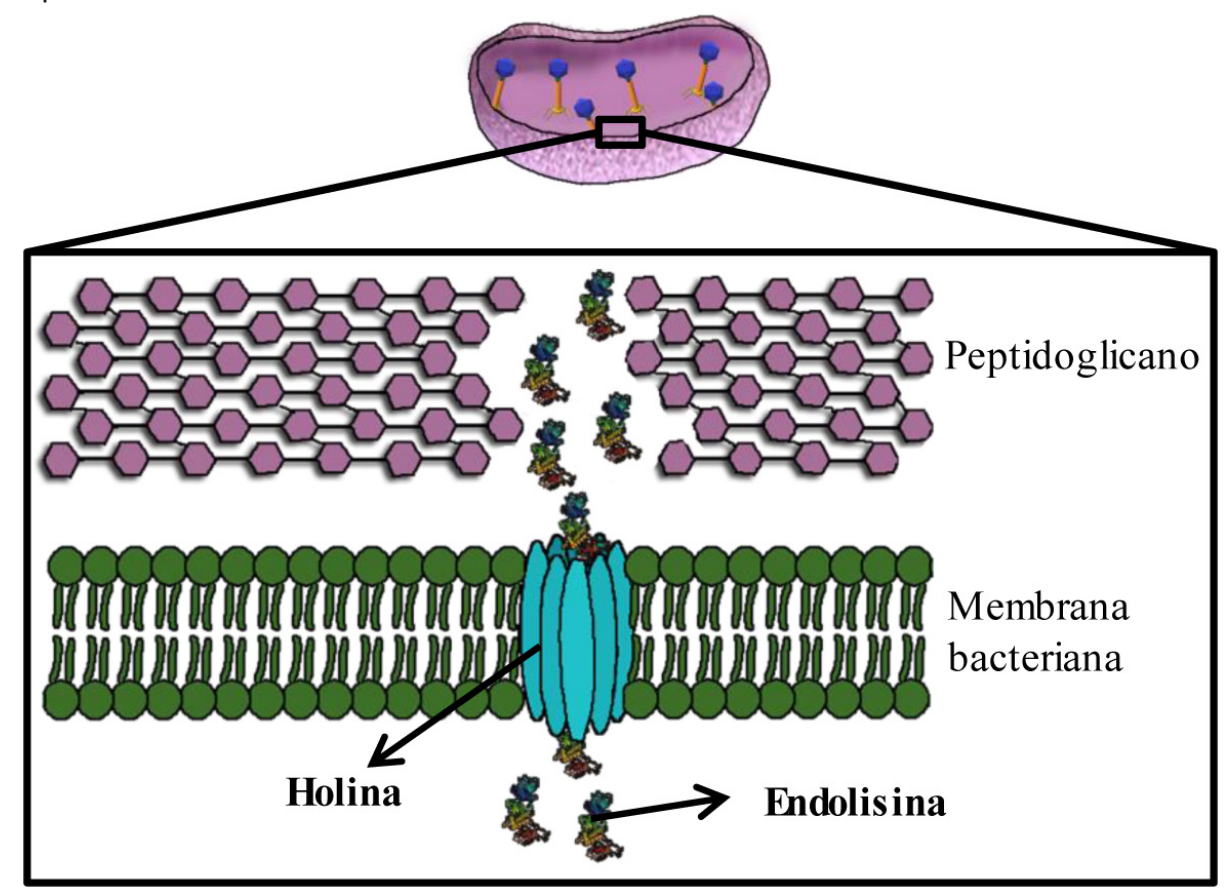

La holina y la endolisina se sintetizan durante la última etapa del ciclo de vida lítico. La holina se integra en la membrana bacteriana formando un poro a través del cual pasará la endolisina y actuará degradando el peptidoglicano. Esto desencadena el aumento de la presión osmótica en el interior del citoplasma y la bacteria explota.

Fuente: elaboración propia. 
bacterias, lo que provoca la aparición de zonas de desestabilización de la envuelta celular incapaces de contener la presión osmótica interna de la célula, que finalmente se lisa. Dependiendo del tipo de enlace químico que hidrolicen, las endolisinas se dividen en cinco tipos: $\mathrm{N}$-acetilmuramoil-L-alanina amidasa, endopeptidasa, N-acetil-ß-D-glucosaminidasa, N-acetilß-D-muramidasa y transglicosilasa.

La estructura de las endolisinas varía entre aquellas codificadas por fagos que infectan a bacterias Gram positivas y las codificadas por fagos que infectan a Gram negativas. Estas últimas son casi siempre proteínas globulares con un solo dominio catalítico. Por el contrario, las endolisinas codificadas por fagos que infectan bacterias Gram positivas tienen una estructura modular compuesta de, al menos, dos dominios funcionales (Fischetti, 2008; Schmelcher, Donovan y Loessner, 2012). Generalmente la actividad catalítica se sitúa en el extremo amino-terminal, mientras que el extremo carboxi-terminal alberga un dominio de unión a la pared celular (cell wall binding domain o CBD) que confiere especificidad al enzima y lo mantiene unido a la pared, evitando la lisis de otras bacterias. La mayoría de las endolisinas tienen un espectro de acción limitado a la especie infectada por el fago que las sintetiza, aunque algunas son específicas de género. Las endolisinas codificadas por fagos que infectan a bacterias Gram positivas tienen la capacidad de degradar el peptidoglicano cuando se añaden desde el exterior de la bacteria (lisis desde fuera), actuando como agentes antibacterianos (Loessner, 2005).

\section{VENTAJAS DE LA UTILIZACIÓN DE BACTERIÓFAGOS Y ENDOLISINAS COMO ANTIMICROBIANOS}

La necesidad de encontrar alternativas a los sistemas habituales de eliminación de patógenos está impulsada por el alarmante aumento de las bacterias resistentes a los antibióticos en ambientes clínicos. Si a esto sumamos el bajo número de nuevos antibióticos descubiertos en los últimos años, no es de extrañar que los fagos y las endolisinas estén siendo objeto de estudio de múltiples laboratorios y empresas (Kutter, Kuhl y Abedon, 2015).

En realidad, la utilización de bacteriófagos como antimicrobianos (también llamada terapia fágica) es una práctica que se inició poco después de su descubrimiento. A principios del siglo XX, Frederick Twort observó una sustancia con capacidad bacteriolítica, siendo Félix d'Herelle quien poco más tarde identificó que se trataba de un virus al que denominó bacteriófago. Ya en aquella época se usaron los fagos en el tratamiento de enfermedades infecciosas, y desde entonces los fagos han sido utilizados en los países de Europa del Este como terapia alternativa a los antibióticos (Sulakvelidze y Kutter, 2005). El hecho de que los bacteriófagos sean capaces de infectar y lisar bacterias resistentes a los antibióticos con la misma eficiencia que lisan bacterias sensibles a los mismos ha propiciado un resurgir de la terapia fágica (Kutter et al., 2010). Aparte de su aplicación en el tratamiento de enfermedades infecciosas en humanos, los bacteriófagos también se están ensayando en multitud de aplicaciones porque, dadas sus características, se postula que son menos perjudiciales que otro tipo de sustancias biocidas.

En el caso de las endolisinas, el descubrimiento de su enorme potencial vino asociado al estudio de sus propiedades enzimáticas (Fischetti, 2008). Así, por ejemplo, la exposición repetida de bacterias a endolisinas no da lugar a la aparición de bacterias resistentes a las mismas (Rodríguez-Rubio, Martínez, Rodríguez et al., 2013; Schuch, Nelson y Fischetti, 2002). Por otra parte, la estructura modular permite el diseño de nuevas proteínas con actividades mejoradas (López, García, García y García, 1997). No obstante, el principal inconveniente de las endolisinas es su falta de actividad frente a bacterias Gram negativas, ya que la membrana externa de las mismas impide el contacto entre la proteína y su sustrato (el peptidoglicano). Este problema ya se ha solventado con el diseño de proteínas quimera que contienen un dominio de naturaleza catiónica, capaz de transportar la proteína a través de la membrana externa hasta el peptidoglicano. A estas proteínas se las ha denominado Artilisinas (Briers y Lavigne, 2015).

Con vistas a la aplicación de bacteriófagos y endolisinas como antimicrobianos, es preciso analizar sus ventajas e inconvenientes, comparándolos con otro tipo de biocidas o antibióticos. Entre las ventajas cabe señalar:

i) La especificidad de los fagos permite una eliminación selectiva de las bacterias patógenas mientras que el resto de la microbiota permanece intacta. En el caso de las endolisinas, la especificidad suele estar restringida al género, es decir, son activas frente a todas las especies del género bacteriano al cual infecta el fago que la codifica. Sin embargo, la efectividad suele ser mucho mayor frente a la especie a la que infecta el fago, y notablemente menor frente al resto de las especies.

ii) La capacidad de auto-replicación de los fagos implica un aumento exponencial en su número tras 
un proceso de infección, multiplicándose así también su eficacia.

iii) Tanto bacteriófagos como endolisinas son igualmente efectivos frente a bacterias sensibles y resistentes a los antibióticos. Por ello, constituyen un prometedor sistema de eliminación de bacterias resistentes a antibióticos que puedan estar presentes en el entorno alimentario.

iv) La actividad antibiofilm de los bacteriófagos y las endolisinas constituye una ventaja a la hora de erradicar estas complejas estructuras microbianas.

v) El uso de bacteriófagos es seguro, ya que hay estudios realizados en personas voluntarias que ingirieron fagos, sin que fuesen detectados efectos adversos (Bruttin y Brussow, 2005).

vi) No alteran las características organolépticas de los alimentos, un requisito muy importante a la hora de ser utilizados como bioconservantes.

Entre las desventajas cabe señalar:

i) Los bacteriófagos pueden ser portadores o transferir genes de virulencia a las bacterias a las cuales infectan. Se precisa, por lo tanto, una caracterización completa previa a su aplicación (secuenciación del genoma completo, identificación de los genes, estudio de la capacidad de transducción). Además, se desaconseja el uso de fagos atemperados, ya que pueden integrarse en el cromosoma bacteriano sin llegar a matar a la bacteria huésped.

ii) Los bacteriófagos tienen un rango de huésped limitado, lo que implica que, en ocasiones, sea necesario utilizar mezclas de fagos para poder eliminar el mayor número posible de cepas distintas de un determinado patógeno.

iii) Las bacterias tienen la capacidad de hacerse resistentes a los bacteriófagos de manera espontánea. Por ello, se requiere siempre el uso de mezclas de fagos de distintas familias, lo que hace virtualmente imposible que una única bacteria adquiera resistencia a todos ellos.

iv) Las condiciones físico-químicas del alimento o del ambiente en el que se procesa, pueden inactivar a bacteriófagos y endolisinas, o bien reducir su actividad, siendo pues necesario determinar las condiciones idóneas para cada aplicación con objeto de garantizar los mejores resultados (Bigwood, Hudson, Billington, CareySmith y Heinemann, 2008).

\section{APLICACIONES DE LOS BACTERIÓFAGOS Y ENDOLISI- NAS EN LA CADENA ALIMENTARIA}

La cadena alimentaria ("de la granja a la mesa") debe ser considerada desde una perspectiva global, ya que los microorganismos patógenos (u otro tipo de sustancias perjudiciales para el consumidor) que entran en cualquiera de los eslabones de la cadena pueden llegar al producto final si no se dispone de los sistemas de detección y eliminación adecuados. Por otra parte, la aplicación de medidas de eliminación de patógenos debe realizarse de acuerdo con los requerimientos necesarios en cada uno de los eslabones de la cadena, teniendo en cuenta las limitaciones legales que existen actualmente respecto al uso de antimicrobianos.

En este contexto, existe abundante bibliografía sobre el estudio de bacteriófagos y endolisinas como agentes de control de bacterias patógenas que ponen en riesgo la seguridad alimentaria tales como Salmonella, Escherichia coli, Staphylococcus aureus, y Campylobacter. Cabe señalar, no obstante, que este campo de estudio es relativamente reciente, por lo que existen multitud de evidencias de su efectividad a escala de laboratorio, pero solo algunos productos fágicos están disponibles comercialmente (Hagens y Loessner, 2010; Moye, Woolston y Sulakvelidze, 2018). Los estudios realizados hasta ahora abarcan todos los eslabones de la cadena de producción del alimento, desde la producción primaria hasta el producto final (véase la figura 3). Además, abordan no solo la utilización de bacteriófagos como antimicrobianos, sino también la detección de bacterias patógenas en los alimentos.

a) Reducción de la carga microbiana en animales de granja. El objetivo es disminuir el número de bacterias zoonóticas en el animal inmediatamente antes de su sacrificio. Generalmente se eliminan bacterias del tracto gastrointestinal, para evitar su transferencia a la carne y a los productos derivados, pero también a los huevos, la leche, etc. La mayoría de los trabajos se han realizado con bacteriófagos frente a patógenos tales como Salmonella, Campylobacter y Escherichia coli 0157:H7 en animales de granja (pollos, cerdos, terneros y corderos) (véase la figura 3). En la mayoría de los casos se obtuvieron resultados satisfactorios después de la administración oral de mezclas de fagos, con una disminución importante de la carga bacteriana, lo que reduce la probabilidad de futura contaminación (revisado recientemente por Carvalho, Costa, Silva y Oliveira, 2017). Para evitar la proliferación de bacterias patógenas en pollos existen dos pro- 
ductos comerciales en Estados Unidos, uno para eliminar Salmonella (PLSV-1 ${ }^{\mathrm{TM}}$ ) y otro para eliminar Clostridium perfringens (INT-401 ${ }^{\mathrm{TM}}$ ) (http://www. intralytix.com/index.php?page=vet). Recientemente otros dos productos (Coli-Pro y Salmo-Pro) han sido aprobados por la Food and Drug Administration (FDA) para administrar a ganado porcino y a aves, respectivamente, evitando así infecciones por estas bacterias, lo que al mismo tiempo permitirá reducir el uso de antibióticos en este sector.

Además, al igual que los fagos, las endolisinas tienen aplicación como antimicrobianos en producción primaria, tanto en profilaxis como para el tratamiento de enfermedades infecciosas. Así, por ejemplo, se han obtenido vacas transgénicas que expresan una endolisina activa frente a Staphylococcus aureus, lo que reduce el riesgo de mastitis y previene la contaminación de la leche por este microorganismo (Donovan, Lardeo y Foster-Frey, 2006). Más recientemente se han obtenido resultados prometedores, aunque preliminares, con la endolisina Trx-SA1. La administración de la proteína (20 mg. por día) en vacas con mastitis subclínica causada por Staphylococcus aureus es efectiva en la curación de la enfermedad (Fan et al., 2016). Además, otra endolisina, activa frente a Streptococcus uberis, no provoca respuesta citotóxica cuando se administra en dosis de

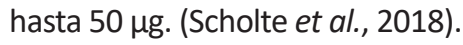

b) Descontaminación de alimentos. Algunos de los sistemas actuales de higienización de los alimentos están basados en altas temperaturas, lo que impide su aplicación en ciertos alimentos

Figura 3. Principales aplicaciones y ejemplos de bacteriófagos comerciales y endolisinas que se pueden aplicar frente a bacterias patógenas a lo largo de la cadena alimentaria

\begin{tabular}{|c|c|}
\hline $\begin{array}{c}\text { Patógenos que causan } \\
\text { enfermedades en animales }\end{array}$ & $\begin{array}{c}\text { Terapia fágica: } \\
\text { prevención y tratamiento }\end{array}$ \\
\hline $\begin{array}{l}\text { - Salmonella } \\
\text { - Clostridiumperfringens } \\
\text { - Staphylococcus aureus } \\
\text { - Eampylobacter } \\
\text { - Escherichia coli } \mathrm{O} 157: \mathrm{H} 7\end{array}$ & 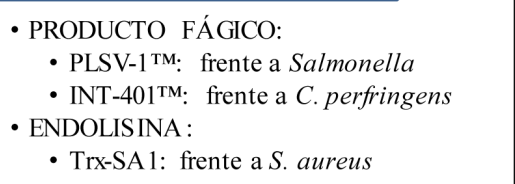 \\
\hline $\begin{array}{l}\text { Patógenos que contaminan } \\
\text { alimentos no procesados }\end{array}$ & $\begin{array}{c}\text { Descontaminación de } \\
\text { alimentos }\end{array}$ \\
\hline $\begin{array}{l}\text { - Listeria monocytogenes } \\
\text { - Salmonella } \\
\text { - Campylobacter } \\
\text { - Shigella } \\
\text { - E. coli } \mathrm{O} 157: \mathrm{H} 7\end{array}$ & $\begin{array}{l}\text { - PRODUCTO FÁGICO: } \\
\text { - EcoShield }{ }^{\mathrm{TM}} \text { : frente a E. coli } \\
\text { - ListShield } \\
\text { - SalmoFresh frente a L. monocytogenes } \\
\text { - ShigActive }{ }^{\mathrm{TM}} \text { : frente a Salmonella a Shigella }\end{array}$ \\
\hline $\begin{array}{c}\text { Patógenos formadores de } \\
\text { biofilms }\end{array}$ & $\begin{array}{c}\text { Desinfección de } \\
\text { superficies industriales }\end{array}$ \\
\hline $\begin{array}{l}\text { - L. monocytogenes } \\
\text { - E. coliO157:H7 } \\
\text { - S. aureus }\end{array}$ & $\begin{array}{l}\text { - PRODUCTO FÁGICO: } \\
\text { - Finalyse }{ }^{\mathrm{TM}} \text { : frente a E. coli } \mathrm{O} 157: \mathrm{H} 7 \text { y } \\
\quad \text { otras E. coli (STEC). }\end{array}$ \\
\hline $\begin{array}{l}\text { Patógenos que contaminan } \\
\text { alimentos procesados }\end{array}$ & Bioconservación \\
\hline $\begin{array}{l}\text { - S. aureus } \\
\text { - L. monocytogenes } \\
\text { - Campylobacter } \\
\text { - Salmonella } \\
\text { - E. coli } \\
\text { - Enterobacter sakazakii }\end{array}$ & $\begin{array}{l}\text { - PRODUCTO FÁGICO: } \\
\text { - PhageGuard STM: frente a Salmonella } \\
\text { - PhageGuard Listex }{ }^{\mathrm{TM}} \text { : frente a L. } \\
\text { monocytogenes } \\
\text { - EcoShield } \\
\text { - ListShield }{ }^{\mathrm{TM}} \text { : frente a } \text { E. coli a } L \text {. monocytogenes } \\
\text { - ENDOLISINA: } \\
\text { - LysH5: frente a } S . \text { aureus } \\
\text { - PlyP100: Frente a L. monocytogenes }\end{array}$ \\
\hline
\end{tabular}


no procesados (carcasas de animales y productos crudos como frutas y verduras). Por ello, se requieren sistemas de desinfección específicos que no alteren sus propiedades organolépticas y que a la vez sean eficaces, ya que algunos de estos productos van a ser consumidos directamente. Los principales patógenos para los que se han utilizado bacteriófagos como descontaminantes son los siguientes: Listeria monocytogenes, Salmonella, Campylobacter, Shigella y Escherichia coli 0157:H7. Las mezclas de fagos se aplicaron sobre alimentos contaminados (tomate, brócoli, espinaca, lechuga, etc.) donde redujeron la carga de bacterias patógenas. Los productos comerciales EcoShield ${ }^{\mathrm{TM}}$ (anteriormente ECP-100), ListShield ${ }^{\mathrm{TM}}$ (anteriormente LMP-102), SalmoFresh $^{\mathrm{TM}}$, ShigActive ${ }^{\mathrm{TM}}$ diseñados frente a Escherichia coli, Listeria monocytogenes, Salmonella y Shigella, respectivamente, han confirmado su eficacia en este tipo de aplicaciones (revisado por Moye et al., 2018).

c) Desinfección de superficies industriales. Las superficies en contacto con los alimentos durante su procesamiento pueden ser una fuente de contaminación por bacterias patógenas. Esto puede deberse a la presencia de estructuras bacterianas (biofilms o biopelículas) sobre dichas superficies, que dificultan la limpieza y desinfección de las mismas. Estas agrupaciones de bacterias, unidas por una matriz extracelular que ellas mismas producen, son extraordinariamente resistentes a los agentes antimicrobianos utilizados convencionalmente para su eliminación. Estudios recientes muestran la eficacia de fagos y endolisinas para eliminar biofilms formados sobre diversos materiales por distintas bacterias como Listeria monocytogenes, Escherichia coli 0157:H7 y Staphylococcus aureus (Gutiérrez, Rodríguez-Rubio, Martínez, Rodríguez y García, 2016). Con este fin, están disponibles varios productos fágicos comerciales. Cabe señalar, por ejemplo, el producto Finalyse ${ }^{\mathrm{TM}}$, compuesto por una mezcla de fagos frente a Escherichia coli 0157:H7 y otras Escherichia coli (STEC) productoras de la toxina Shiga, que se comercializa como desinfectante para instalaciones de ganado vacuno (http:// www.passportfoodsafety.com/finalyse).

Las endolisinas también pueden tener aplicación como desinfectantes en el entorno de la industria alimentaria, ya que han demostrado su eficacia en la eliminación de biofilms de diversos pató- genos en ensayos de laboratorio. Los fagos y las endolisinas comparten, además, la ventaja frente a los desinfectantes clásicos de evitar los efectos tóxicos que el vertido de este tipo de sustancias químicas ocasiona en el ambiente.

d) Aumento de la vida útil de los alimentos. Con objeto de inhibir el desarrollo de bacterias patógenas en el alimento procesado, los fagos y sus enzimas líticos serían utilizados como bioconservantes. Se ha comprobado que los bacteriófagos son capaces de impedir el desarrollo de patógenos tales como Staphylococcus aureus, Listeria monocytogenes, Campylobacter, Salmonella, Escherichia coli o Enterobacter sakazakii en leche, queso, carnes y varios alimentos listos para comer (revisado por Endersen et al., 2014). Tal es su eficacia, que ya han sido aprobados (por la FDA) varios productos para su uso como conservantes de alimentos, entre los que cabe citar PhageGuard $\mathrm{S}^{\mathrm{TM}}$, PhageGuard Listex ${ }^{\mathrm{TM}}$ (https://www.phageguard.com/), EcoShield $^{\mathrm{TM}}$, ListShield ${ }^{\mathrm{TM}}$.

En lo que respecta a la aplicación de endolisinas como conservantes, se han llevado a cabo varios trabajos con resultados interesantes. Por ejemplo, la endolisina LysH5 muestra una gran actividad frente a Staphylococcus aureus en productos lácteos (Obeso, Martínez, Rodríguez y García, 2008), así como la proteína lítica recombinante derivada del mismo fago (CHAP-SH3b), (Rodríguez-Rubio, Martínez, Donovan et al., 2013). Además, la sinergia de la endolisina PlyP100 con otros bioconservantes, como la nisina (E-234) permite la eliminación de Listeria. monocytogenes en queso fresco (Ibarra-Sanchez, Van Tassell y Miller, 2018). Este tipo de proteínas se pueden combinar incluso con altas presiones (Misiou, van Nassau, Lenz y Vogel, 2018).

Debido a su alta especificidad, las endolisinas se han utilizado también en alimentos fermentados, sin que la presencia de estos antimicrobianos interfiera en los cultivos iniciadores. Un ejemplo es el uso de cultivos iniciadores protectores, en el que las endolisinas son secretadas por Lactococcus lactis para evitar la contaminación por Staphylococcus aureus y por Listeria monocytogenes (Gaeng, Scherer, Neve y Loessner, 2000; Rodríguez-Rubio, Gutiérrez, Martínez, Rodríguez y García, 2012).

e) Detección de bacterias patógenas. La especificidad de los fagos por la bacteria huésped ha per- 
mitido desarrollar sistemas de detección de patógenos muy eficaces desde hace tiempo. No obstante, estos sistemas han sufrido recientemente un enorme impulso mediante su utilización como biosensores, capaces de detectar a la bacteria cuando se encuentra incluso en una concentración muy baja y en un período de tiempo corto (revisado por Richter, Janczuk-Richter, NiedziolkaJonsson, Paczesny y Holyst, 2018).

Estos biosensores utilizan también endolisinas, en concreto el motivo de unión a sustrato CBD que, además de especificidad, muestra una alta afinidad por el peptidoglicano de la bacteria huésped del fago del cual deriva la endolisina. Así, por ejemplo, es posible detectar un número bajo de células de Listeria monocytogenes (100 CFU) a partir de un alimento y en poco tiempo (Kretzer, Schmelcher y Loessner, 2018). Otro ejemplo destacable es la detección de las cepas de Clostridium asociadas a la hinchazón tardía del queso (Gomez-Torres et al., 2018), que incluso permite seguir la evolución de Clostridium tyrobutyricum durante la maduración del queso (Gómez-Torres, Ávila, Narbad, Mayer y Garde, 2019).

\section{PERSPECTIVAS DE FUTURO}

Los estudios realizados hasta el momento con bacteriófagos y endolisinas claramente demuestran su potencial para mejorar la seguridad de los alimentos. Al mismo tiempo, su contribución a la disminución del uso de antibióticos y desinfectantes, que ponen en peligro la sostenibilidad de los sistemas de producción de alimentos, es también una importante ventaja que hay que tener en cuenta. Sin embargo, la implantación final de estos nuevos sistemas de conservación y de desinfección va a estar condicionada por aspectos relacionados no solo con su eficiencia en las diferentes aplicaciones, sino también con la aprobación por parte de las autoridades correspondientes, lo que en la Unión Europea no resulta fácil, a diferencia de lo que ocurre en Estados Unidos, por poner un ejemplo concreto.

Por ello, y de cara al futuro inmediato, es preciso reforzar ciertos aspectos como el mejor conocimiento de los efectos que un uso intensivo de estos antimicrobianos podría llegar a tener, en el caso de la ganadería, si llegan a utilizarse como productos sanitarios.

En lo que se refiere a la investigación, es imprescindible realizar un estudio exhaustivo de la biología de los bacteriófagos que vayan a ser utilizados en este sector. Esto incluye la secuenciación de los genomas, a fin de descartar la presencia de genes de virulencia que pudieran ser transferidos a la población bacteriana. Otro dato que se debe tener en cuenta es la naturaleza de los fagos, ya que es preferible utilizar fagos virulentos que fagos atemperados. Asimismo, han de evitarse fagos capaces de llevar a cabo procesos de transducción generalizada que pudieran dispersar genes de virulencia o de resistencia a antibióticos. Además, es necesario optimizar adecuadamente los procesos de propagación y purificación a gran escala de los bacteriófagos, a fin de rentabilizar su uso. En situación similar se encuentran las endolisinas, ya que el escalado de la producción y purificación de las mismas es uno de los principales inconvenientes de cara a su utilización futura.

La aprobación del uso de bacteriófagos y endolisinas por parte de las autoridades de la Unión Europea va a depender en gran medida de la existencia de estudios que avalen no solo su eficacia, sino también su inocuidad. En este sentido, es necesario realizar estudios sobre los efectos del consumo de estos productos en la microbiota intestinal, así como análisis de citotoxicidad e inmunogenicidad. Hasta ahora no se han descrito efectos adversos tras la administración oral de fagos (Bruttin y Brussow, 2005; Sarker et al., 2012). Sin embargo, no existen datos respecto a la administración de endolisinas. El hecho de que existan varios productos comerciales junto con el gran número de empresas biotecnológicas dedicadas al desarrollo de productos fágicos con aplicaciones diversas en distintos países permite ser optimistas respecto a la aprobación por la Unión Europea de este tipo de antimicrobianos en un futuro próximo.

Finalmente, la aceptación por parte de las empresas del sector agroalimentario depende de una serie factores técnicos entre los que cabe señalar la identificación de los métodos de aplicación óptimos, la incorporación de estos nuevos tratamientos a los puntos críticos de control (APPCC), la obtención de preparaciones de bacteriófagos altamente concentradas para mejorar su eficacia. También depende en gran medida de otros problemas no técnicos, como por ejemplo la evaluación de la eficacia del tratamiento con fagos en relación al coste de fabricación del alimento y a la aceptación por parte del consumidor (Sulakvelidze, 2013).

Con respecto a la aceptación del consumidor, es posible que el uso de endolisinas pueda ser más fácilmente aceptado, particularmente en bioconservación. A pesar de ello, la aceptación pasa por garantizar 
la inactivación de los fagos (que son percibidos como perjudiciales) a lo largo del proceso de fabricación del alimento, de manera que no lleguen al consumidor. Esto sería factible siempre y cuando esta eliminación no implique un incremento excesivo del coste del alimento, que necesariamente repercutiría en el precio pagado por el consumidor.
En definitiva, es preciso disponer de numerosos datos adicionales que disipen cualquier duda que las autoridades competentes puedan tener para aprobar la aplicación de este tipo de antimicrobianos. Asimismo, es necesario hacer tareas de divulgación en el sector de la alimentación y entre los consumidores para favorecer la aceptación de los mismos.

\section{BIBLIOGRAFÍA}

Ackermann, H. W. (2007). 5500 Phages examined in the electron microscope. Archives of Virology, 152, pp. 227-243. https:// doi.org/10.1007/s00705-006-0849-1

Bigwood, T., Hudson, J. A., Billington, C., Carey-Smith, G. V. y Heinemann, J. A (2008). Phage inactivation of foodborne pathogens on cooked and raw meat. Food Microbiolology, 25, pp. 400-406. https://doi.org/10.1016/j. fm.2007.11.003

Bore, E., Hebraud, M., Chafsey, I., Chambon, C., Skjaeret, C., Moen, B. y Langsrud, S. (2007). Adapted tolerance to benzalkonium chloride in Escherichia coli K-12 studied by transcriptome and proteome analyses. Microbiology 153, pp. 935-946.

Briers, Y. y Lavigne, R. (2015). Breaking barriers: expansion of the use of endolysins as novel antibacterials against Gram-negative bacteria. Future Microbiology, 10, pp. 377-390. https://doi. org/10.2217/fmb.15.8

Bruttin, A. y Brussow, H. (2005). Human volunteers receiving Escherichia coli phage T4 orally: a safety test of phage therapy. Antimicrobial Agents and Chemotherapy, 49, pp. 2874-2878. https://doi. org/10.1128/AAC.49.7.2874-2878.2005

Brüssow, H. y Kutter, E. (2005). Phage ecology. En: Kutter, E. y Sulakvelidze, A. (eds.). Bacteriophages: Biology and Application. Boca Raton, Florida: CRC Press, pp. 129-164.

Carvalho, C., Costa, A. R., Silva, F. y Oliveira, A. (2017). Bacteriophages and their derivatives for the treatment and control of food-producing animal infections. Critical Reviews in Microbiology, 43, pp. 583-601. https://doi.org/10.1080/1040 841X.2016.1271309

Catalao, M. J., Gil, F., Moniz-Pereira, J., SaoJose, C. y Pimentel, M. (2013). Diversity in bacterial lysis systems: bacteriophages show the way. FEMS Microbiology Reviews, 37, pp. 554-571. https://doi. org/10.1111/1574-6976.12006
Donovan, D. M., Lardeo, M. y FosterFrey, J. (2006). Lysis of staphylococcal mastitis pathogens by bacteriophage phi11 endolysin. FEMS Microbiology Letters, 265, pp. 133-139. https://doi. org/10.1111/j.1574-6968.2006.00483.x

European Food Safety Authority and European Centre for Disease Prevention and Contro (EFSA and ECDC) (2017). The European Union summary report on trends and sources of zoonoses, zoonotic agents and food-borne outbreaks in 2016. EFSA Journal, 15 (12), e05077.

Endersen, L., O'Mahony, J., Hill, C., Ross, R. P., McAuliffe, O. y Coffey, A. (2014). Phage therapy in the food industry. Annual Review of Food Science and Technology, 5, pp. 327-349. https://doi.org/10.1146/ annurev-food-030713-092415

Fan, J., Zeng, Z., Mai, K., Yang, Y., Feng, J., Bai, Y., Sun, B., Xie, Q., Tong, Y. y Ma, J. (2016). Preliminary treatment of bovine mastitis caused by Staphylococcus aureus, with trx-SA1, recombinant endolysin of S. aureus bacteriophage IME-SA1. Veterinary Microbiology, 191, pp. 65-71. https:// doi.org/10.1016/j.vetmic.2016.06.001

Fischetti, V. A. (2008). Bacteriophage lysins as effective antibacterials. Current Opinion in Microbiology, 11, pp. 393-400. https://doi.org/10.1016/j. mib.2008.09.012

Gaeng, S., Scherer, S., Neve, H. y Loessner, M. J. (2000). Gene cloning and expression and secretion of Listeria monocytogenes bacteriophage-lytic enzymes in Lactococcus lactis. Applied and Environmental Microbiology, 66, pp. 2951-2958. https://doi.org/10.1128/ aem.66.7.2951-2958.2000

Gómez-Torres, N., Ávila, M., Narbad, A., Mayer, M. J. y Garde, S. (2019). Use of fluorescent CTP1L endolysin cell wallbinding domain to study the evolution of Clostridium tyrobutyricum during cheese ripening. Food Microbiology, 78, pp. 11-17. https://doi.org/10.1016/j. fm.2018.09.018
Gómez-Torres, N., Dunne, M., Garde, S., Meijers, R., Narbad, A., Ávila, M. y Mayer, M. J. (2018). Development of a specific fluorescent phage endolysin for in situ detection of Clostridium species associated with cheese spoilage. Microbial Biotechnology, 11, pp. 332-345. https://doi. org/10.1111/1751-7915.12883

Gutiérrez, D., Rodríguez-Rubio, L., Martínez, B., Rodríguez, A. y García, P. (2016). Bacteriophages as weapons against bacterial biofilms in the food industry. Frontiers in Microbiology, 7, 825. https://doi. org/10.3389/fmicb.2016.00825

Hagens, S. y Loessner, M. J. (2007). Application of bacteriophages for detection and control of foodborne pathogens. Applied Microbiology and Biotechnology, 76, pp. 513-519. https://doi. org/10.1007/s00253-007-1031-8

Ibarra-Sánchez, L. A., Van Tassell, M. L. y Miller, M. J. (2018). Antimicrobial behavior of phage endolysin PlyP100 and its synergy with nisin to control Listeria monocytogenes in Queso Fresco. Food Microbiology, 72, pp. 128-134. https:// doi.org/10.1016/j.fm.2017.11.013

Kretzer, J. W., Schmelcher, M. y Loessner, M. J. (2018). Ultrasensitive and fast diagnostics of viable Listeria cells by CBD magnetic separation combined with $A 511$ : IUxAB detection. Viruses, 10 (11), 626. https://doi.org/10.3390/ v10110626

Kutter, E., De Vos, D., Gvasalia, G., Alavidze, Z., Gogokhia, L., Kuhl, S. y Abedon, S. T. (2010). Phage therapy in clinical practice: treatment of human infections. Current Pharmaceutical Biotechnology, 11, pp. 69-86.

Kutter, E. M., Kuhl, S. J. y Abedon, S. T. (2015). Re-establishing a place for phage therapy in western medicine. Future Microbiology, 10, pp. 685-688. https:// doi.org/10.2217/fmb.15.28

Loessner, M. J. (2005). Bacteriophage endolysins--current state of research and applications. Current Opinion in Micro- 
biology, 8, pp. 480-487. https://doi. org/10.1016/j.mib.2005.06.002

López, R., García, E., García, P. y García, J. L. (1997). The pneumococcal cell wall degrading enzymes: a modular design to create new lysins? Microbial Drug Resistance, 3, pp. 199-211.

Manrique, P., Dills, M. y Young, M. J. (2017). The human gut phage community and its implications for health and disease. Viruses, 9 (6), 141. https://doi.org/10.3390/v9060141

Misiou, O., van Nassau, T. J., Lenz, C. A. y Vogel, R. F. (2018). The preservation of Listeria-critical foods by a combination of endolysin and high hydrostatic pressure. International Journal of Food Microbiology, 266, pp. 355-362. https://doi.org/10.1016/j.ijfoodmicro.2017.10.004

Moye, Z. D., Woolston, J. y Sulakvelidze, A. (2018). Bacteriophage applications for food production and processing. Viruses, 10 (4), 205. https://doi. org/10.3390/v10040205

Obeso, J. M., Martínez, B., Rodríguez, A. y García, P. (2008). Lytic activity of the recombinant staphylococcal bacteriophage PhiH5 endolysin active against Staphylococcus aureus in milk. International Journal of Food Microbiology, 128, pp. 212-218. https://doi.org/10.1016/j. ijfoodmicro.2008.08.010

Richter, L., Janczuk-Richter, M., NiedzioIka-Jonsson, J., Paczesny, J. y Holyst, R. (2018). Recent advances in bacteriophage-based methods for bacteria detection. Drug Discovery Today, 23, pp. 448-455. https://doi.org/10.1016/j. drudis.2017.11.007
Rodríguez-Rubio, L., Gutiérrez, D., Martínez, B., Rodríguez, A. y García, P. (2012). Lytic activity of LysH5 endolysin secreted by Lactococcus lactis using the secretion signal sequence of bacteriocin Lcn972. Applied and Environmental Microbiology, 78, pp. 3469-3472. https:// doi.org/10.1128/AEM.00018-12

Rodríguez-Rubio, L., Martínez, B., Donovan, D. M., García, P. y Rodríguez, A. (2013). Potential of the virion-associated peptidoglycan hydrolase HydH5 and its derivative fusion proteins in milk biopreservation. PLoS One, 8, e54828. https:// doi.org/10.1371/journal.pone.0054828

Rodríguez-Rubio, L., Martínez, B., Rodríguez, A., Donovan, D. M., Gotz, F. y García, P. (2013). The phage lytic proteins from the Staphylococcus aureus bacteriophage vB_SauS-philPLA88 display multiple active catalytic domains and do not trigger staphylococcal resistance. PLoS One, 8, e64671. https://doi. org/10.1371/journal.pone.0064671

Sao-Jose, C., Parreira, R., Vieira, G. y Santos, M. A. (2000). The $\mathrm{N}$-terminal region of the Oenococcus oeni bacteriophage fOg44 lysin behaves as a bona fide signal peptide in Escherichia coli and as a cis-inhibitory element, preventing lytic activity on oenococcal cells. Journal of Bacteriology, 182, pp. 5823-5831. https://doi. org/10.1128/jb.182.20.5823-5831.2000

Sarker, S. A., McCallin, S., Barretto, C., Berger, B., Pittet, A. C., Sultana, S., Krause, L., Huq, S., Bibiloni, R., Bruttin, A., Reuteler, G. y Brussow, H. (2012). Oral T4-like phage cocktail application to healthy adult volunteers from Bangladesh. Virology, 434, pp. 222-232. https://doi. org/10.1016/j.virol.2012.09.002
Schmelcher, M., Donovan, D. M. y Loessner, M. J. (2012). Bacteriophage endolysins as novel antimicrobials. Future Microbiology, 7, pp. 1147-1171. https://doi. org/10.2217/fmb.12.97

Scholte, C. M., Nelson, D. C., Garcia, M., Linden, S. B., Elsasser, T. H., Kahl, S., Qu, Y. y Moyes, K. M. (2018). Short communication: Recombinant bacteriophage endolysin PlyC is nontoxic and does not alter blood neutrophil oxidative response in lactating dairy cows. Journal of Dairy Science, 101, pp. 6419-6423. https://doi. org/10.3168/jds.2017-13908

Schuch, R., Nelson, D. y Fischetti, V. A. (2002). A bacteriolytic agent that detects and kills Bacillus anthracis. Nature, 418, pp. 884-889. https://doi. org/10.1038/nature01026

Sulakvelidze, A. (2013). Using lytic bacteriophages to eliminate or significantly reduce contamination of food by foodborne bacterial pathogens. Journal of the Science of Food and Agriculture, 93, pp. 3137-3146. https://doi. org/10.1002/jsfa.6222

Sulakvelidze, A. y Kutter, E. (2005). Bacteriophage therapy in humans. En: Kutter, E. y Sulakvelidze, A. (eds.). Bacteriophages: biology and application. Boca Raton, Florida: CRC Press, pp. 381-436.

\section{Recursos en línea}

Centers for Disease Control and Prevention (CDC). Foodborne Diseases Active Surveillance Network (FoodNet): FoodNet 2015 Annual Foodborne Illness Surveillance Report. [En línea]. Disponible en https:// www.cdc.gov/foodnet/reports/annualreports-2015.html 